\title{
PROGRESSIVE LIQUEFACTION PROCESS OF LOOSELY DEPOSITED SAND BED UNDER OSCILLATING WATER PRESSURE ON ITS SURFACE
}

\author{
Yuezeng $\mathrm{YU}^{1}$, Shiro MAENO ${ }^{2}$ and Hiroshi NAGO \\ ${ }^{1}$ Student Member of JSCE, Graduate Student, Graduate School of Natural Science \& Technology, Okayama University \\ (3-1-1, Tsushima-Naka, Okayama 700-8530,Japan) \\ ${ }^{2}$ Member of JSCE, Dr. Eng., Associate Professor, Dept. of Environmental \& Civil Engineering, Okayama University \\ (3-1-1, Tsushima-Naka, Okayama 700-8530,Japan) \\ ${ }^{3}$ Member of JSCE, Dr. Eng., Professor, Dept. of Environmental \& Civil Engineering, Okayama University
}

(3-1-1, Tsushima-Naka, Okayama 700-8530,Japan)

\begin{abstract}
In this paper, the progressive liquefaction process of the loosely deposited sand bed under oscillating water pressure on its surface is investigated theoretically by using the vertically one-dimensional model, in which the elasto-plasticity of the sand bed skeleton is taken into account. The changes of pore water pressure, effective stress and liquefaction depth in the sand bed with time are simulated during the initial time period after the cyclic pressure loading. The experimental results verified that the proposed analytical model expressed fairly well the progressive liquefaction process of the sand bed.
\end{abstract}

Key Words : liquefaction, pore water pressure, effective stress, loose sand, oscillating water pressure

\section{INTRODUCTION}

When the water pressure acting on the surface of a loosely deposited sand bed changes, the pore water pressure in the sand bed also changes with time, and as a result, the excess pore water pressure will occur. An increase in the excess pore pressure leads a decrease in the effective stress. Under certain conditions, the value of the effective stress may become zero, that is, the liquefaction will come about. The liquefaction will lead to the loss of the bearing capacity of the sand bed and the failure of hydraulic structure on the sand bed.

The theoretical studies on the pore water pressure and liquefaction of sand bed under waves or oscillating water pressure on its surface have been seen in many literatures. In the early time, the studies are all based on the assumptions of the incompressible pore-fluid, the rigid porous sand skeleton and the flow in the porous bed in accordance with Darcy's law. In last thirty years, studies are carried out under such assumptions that the pore-fluid is compressible and the sand skeleton is the poro-elastic material. (Madsen ${ }^{1)}$, Yamamoto et $\mathrm{al.}^{2)}, \mathrm{Nago}^{3)}$, Nago \& Maeno ${ }^{4), 5)}$, Okusa ${ }^{6)}$, Sakai ${ }^{7)}$, Miura et al. ${ }^{8}$, Sassa et al. ${ }^{97}$ ).

Yamamoto et al. ${ }^{2)}$ have treated for a saturated seabed of infinite depth with isotropic permeability, Madsen $^{1)}$ for that with anisotropic permeability and Okusa $^{6}$ for unsaturated submarine sediment with the assumption of plane strain conditions of uniform elastic material.

Sakai $^{7)}$ graphically showed the applicability of three solutions for the transient wave-induced pore water pressure in seabed: the seepage flow solution, the exact solution and the boundary region approximation solution of Biot's consolidation equations, by the non-dimensional parameter for surf zone conditions

$\mathrm{Nago}^{3)}$ built basic equations describing the dynamic behavior of sand bed with one-dimensional model. In the equations, the effect of pore air is considered.

Zen et al. ${ }^{10)}$ investigated the liquefaction problem related to oscillatory pore pressure with onedimensional model.

Oka et al. ${ }^{11)}$, Kuwabara et al. ${ }^{12)}$, Sekiguchi et al. ${ }^{13)}$ investigated the response of sand bed to wave based 


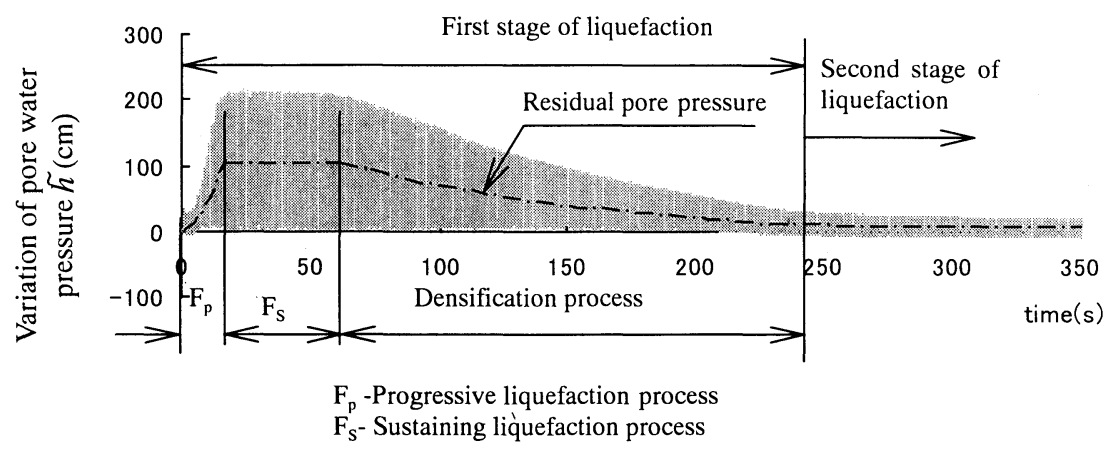

Fig.1 (a) Pore water pressure measured in the loose sand bed

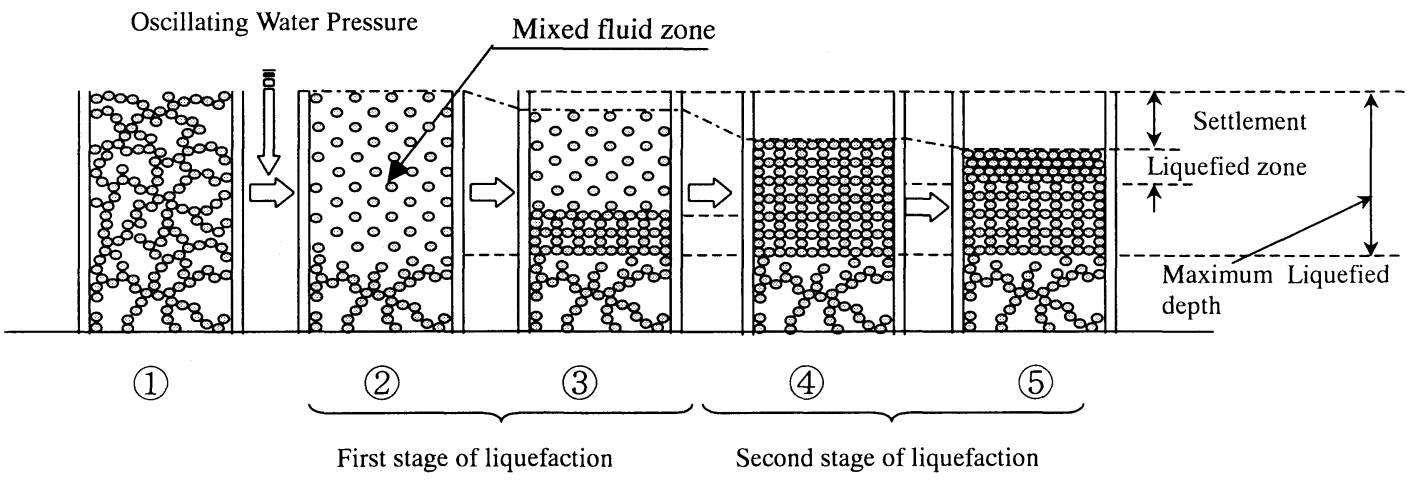

Fig.1 (b) Liquefaction and densification process

on the assumptions that the pore-fluid is compressible and the sand skeleton is an elastoplastic material.

Sekiguchi et al. ${ }^{13)}$ derived a closed-form solution related to the wave-induced pore pressure variation in sand bed through the assumption about plastic volumetric strain.

Nago \& Maeno ${ }^{14)}$ classified the liquefaction process of a loosely deposited sand bed into the following two stages of liquefaction through the study of the pore water pressure measured in the sand bed.

The first is the sustained liquefaction with the build up of excess pore pressure, which appears in the initial stage of cyclic loading. In this stage, excess pore pressure includes both oscillatory pore pressure and residual pore pressure. It is called as the first stage of liquefaction, in which the sand bed behaves like a fluid with a density of the mixture composed of sand and water. Residual pore pressure results from the plastic deformation of the sand bed, which is equal to the temporal average of excess pore pressure over any wave cycle (See Fig.1(a)).

The second is the cyclic transient liquefaction with the damping of amplitude and the lag of phase in the pore water pressure, which occurs after the first stage of liquefaction. In this stage, the sand bed has become denser, and excess pore pressure contains only oscillatory pore pressure. Residual pore pressure does not occur. It is called as the second stage of liquefaction.

The pore water pressure measured at a point in a loosely deposited sand bed is shown in Fig.1 (a). It is understood from Fig.1 (a) that the first stage of liquefaction is composed of three parts, that is, progressive liquefaction process with the increase of the residual pore pressure, sustaining liquefaction process without the damping in amplitude and lag in phase of oscillatory pore pressure, and densification process with the dissipation of the residual pore pressure. During the second stage of liquefaction, the residual pore pressure disappears.

The mechanism of liquefaction and densification processes of the loosely deposited sand bed under oscillating water pressure can be explained schematically as shown in Fig.1(b). (1)The initial state of the loosely deposited sand bed; (2) The loosely deposited sand bed is liquefied and the fluid state of a mixture of sand and water is formed; (3) After the liquefaction depth reaches its maximum value, the sand layer gradually recovers with 
sedimentation of sand in the mixed fluid zone; (4) The sedimentary sand layer reaches to the sand surface in a very short time, and the sand layer is densified during this stage; (5)The second stage of liquefaction and densification begin in the upper zone of the sand bed.

The above mentioned researches on the dynamic behavior of the sand bed considering soil-waterstructure interaction are mainly on the second stage of liquefaction. The theoretical research on the second stage of liquefaction seems to be almost accomplished, and many research achievements are obtained. Whereas the mechanism of the first stage of liquefaction, in which the liquefaction depth of sand bed varies with time under oscillating water pressure, is not yet clear theoretically. The determination of the varying process of pore water pressure and effective stress is considered very important to recognize the destruction mechanism of hydraulic structures surrounded by such a sand bed under oscillating water pressure and to search preventive measures against the collapse of such structures. In this paper, the progressive liquefaction process of the first stage of liquefaction is treated theoretically and experimentally by means of the vertically one-dimensional model.

\section{THEORETICAL INVESTIGATION}

\section{(1) Definition of excess pore pressure}

As shown in Fig.2, supposing that the oscillating water pressure at the interface of fluid and sand layer, denoted by water head $h_{v}$, causes the varying pore pressure (in water head $h$ ) at a point of interest in the sand bed. The pore pressure varies from the average hydrostatic pressure with time. In the case that sand bed is not yet liquefied, that is, there exists not a sustaining liquefaction zone, the varying curve of pore pressure is shown as (1) in Fig.2.

Pore water pressure $h$ at a point of depth $y$ can be described by the formula below.

$$
h=h_{0}+h_{v}+y+h^{\prime}
$$

where, $h_{0}$ is the water depth of still water level, $h^{\prime}$ denotes oscillatory excess pore pressure in water head

Moving the hydrostatic pressure terms corresponding to the still water level $\left(h_{0}+y\right)$ to the left hand side of Eq.(1), one obtains

$$
h-\left(h_{0}+y\right)=h_{v}+h^{\prime}
$$

The sum of terms in left hand side of Eq.(2) means the variation of pore water pressure in water head, denoted by $\tilde{h}$, then Eq.(2) can be rewritten as follows.

$$
\tilde{h}=h_{v}+h^{\prime}
$$

where, $\tilde{h}$ expresses the variation of pore water pressure $\left(\tilde{h}=h-h_{0}-y\right)$.

When the upper sand layer is liquefied, that is, the sustaining liquefaction zone is formed, the varying curve of pore pressure is shown as (2) in Fig.2.

Pore water pressure $h$ at a point of depth $y$ in sand bed can be described as,

$$
\begin{aligned}
\rho_{w} g h= & \rho_{w} g h_{s}+\rho_{m} g y_{*_{0}} \\
& +\rho_{w} g\left\{\left(y-y_{*_{0}}\right)+h^{\prime}\right\} \\
& h_{s}=h_{0}+h_{v} \\
\rho_{m} & =\rho_{s}(1-n)+\rho_{w} n_{w}
\end{aligned}
$$

where,

$h_{s}$ : water head acting on the sand surface

$\rho_{m}$ : density of mixture composed of sand and water

$\rho_{w}:$ density of water

$\rho_{s}:$ density of an individual sand grain

$n \quad$ : porosity in sand bed

$n_{w}$ : porosity occupied by pore water in sand bed

$g \quad:$ acceleration due to gravity

$y_{*_{0}}:$ the liquefied depth of the sand bed

The following equation for pore pressure can be derived from the above relations (4).

$$
h=h_{0}+h_{v}+y+\frac{(1-n)\left(\rho_{s}-\rho_{w}\right)}{\rho_{w}} y_{* 0}+h^{\prime}
$$

Moving the first term and the third term on the right hand side of Eq.(5) to the left hand side and applying the previous expression $\left(\tilde{h}=h-h_{0}-y\right)$, Eq.(5) can be rewritten as

$$
\tilde{h}=\frac{(1-n)\left(\rho_{s}-\rho_{w}\right)}{\rho_{w}} y_{* 0}+h_{v}+h^{\prime}
$$

Furthermore, Eq.(6) is represented with the following form.

$$
\tilde{h}=\tilde{h}^{(1)}+\tilde{h}^{(2)}
$$

where,

$$
\tilde{h}^{(1)}=\frac{(1-n)\left(\rho_{s}-\rho_{w}\right)}{\rho_{w}} y_{*_{0}} \text { stands for the residual }
$$

pore pressure, which is caused by the weight of mixture fluid in the upper liquefied zone.

$\tilde{h}^{(2)}=h_{\nu}+h^{\prime}$ represents the oscillatory pore pressure, whose temporal average over any wave cycle is zero in consideration.

The oscillatory excess pore pressure $h^{\prime}$ at the point is denoted by

$$
h^{\prime}=\tilde{h}-\frac{(1-n)\left(\rho_{s}-\rho_{w}\right)}{\rho_{w}} y_{*_{0}}-h_{v}
$$




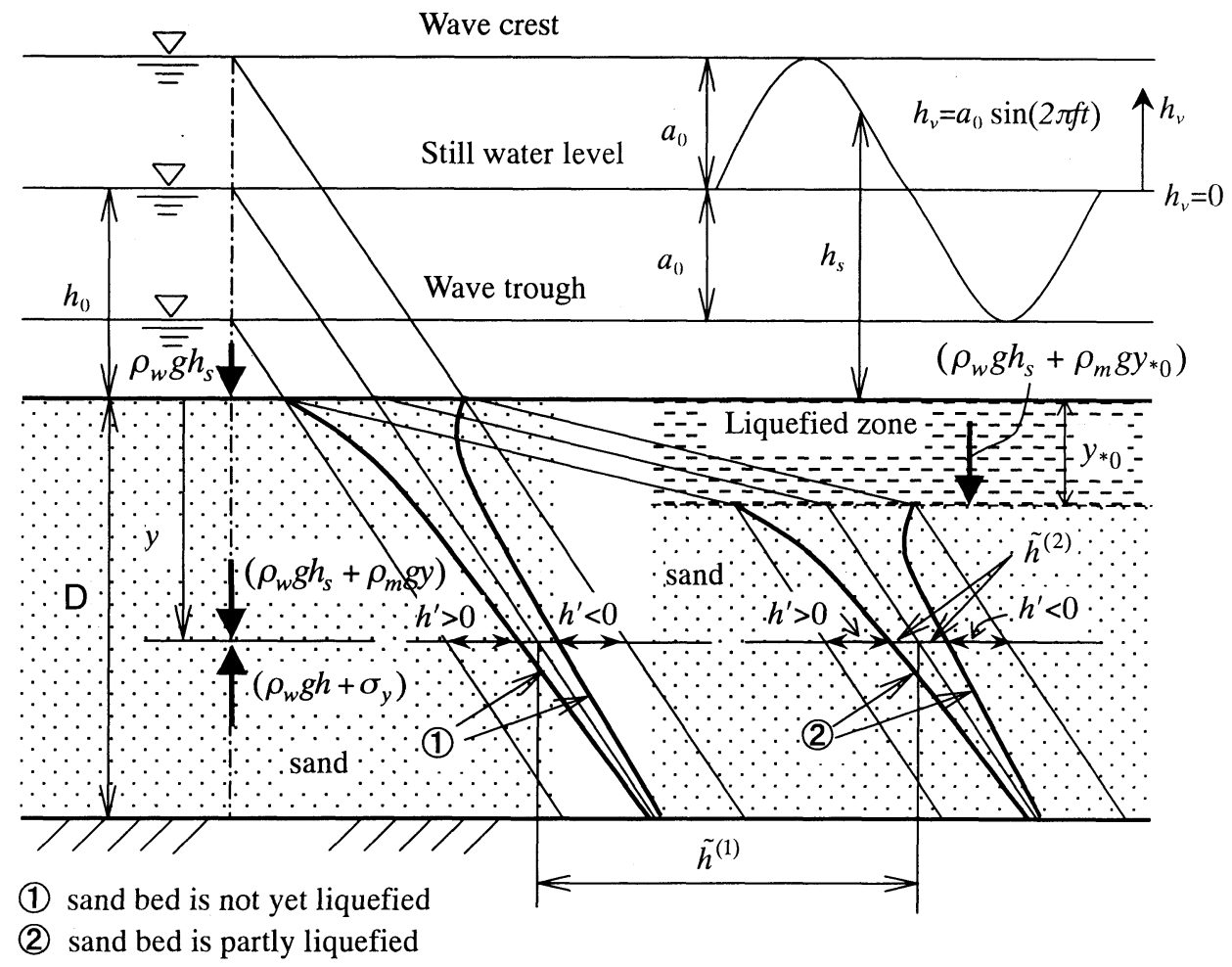

Fig. 2 Sand bed model and pore water pressure Eq.(1).

When $y_{*_{0}}=0$, Eq.(5) becomes the same form as

\section{(2) Governing Equations}

A vertically one-dimensional sand bed model is used to determine the basic characteristics of the dynamic behavior of a loosely deposited sand bed under oscillating water pressure. The excess pore pressure and the effective stress in the loosely deposited sand bed are analyzed with the governing equation already given in the literature ${ }^{3)}$.

The assumptions applied in this literature are as follows.

1) The sand bed is composed of three phases; sand grains, water and air. The porosity $n$ is the sum of the parts of water, $n_{w}$, and air, $n_{a}$., That is,

$$
n=n_{\mathrm{w}}+n_{\mathrm{a}}
$$

2) The sand bed is highly saturated; therefore, the amount of air present is considered to be very small in comparison to the total volume of the porous part. That is,

$$
n_{a}<n
$$

3) The skeleton of the sand bed is deformed in accordance with Hooke's law, but the deformation of the sand grains themselves is negligible.

4) The density of water changes with the compressibility, $\beta$.

5) The volume of air changes in accordance with Boyle's law.

6) The pore water moves in accordance with Darcy's law.

The governing equation that expresses the behavior of excess pore pressure in the sand bed was obtained by $\mathrm{Nago}^{3)}$ :

$$
\left(\alpha+\beta n_{w}+\frac{n_{a}}{P}\right) \frac{\partial h^{\prime}}{\partial t}+\left(\beta n_{w}+\frac{n_{a}}{P}\right) \frac{\partial h_{s}}{\partial t}=\frac{k}{\rho_{w} g} \frac{\partial^{2} h^{\prime}}{\partial y^{2}}
$$

where,

$P \quad:$ absolute pressure $\left(P=P_{0}+p\right)$

$P_{0}:$ atmospheric pressure

$\alpha$ : elastic compressibility of the skeleton of sand bed

$\beta$ : compressibility of water

$k \quad$ : permeability coefficient of sand bed

Eq.(11) is sufficient to find the unknown variable $h^{\prime}$. However, it is convenient for the numerical analysis that the equation (11) is transformed into the system of equations involving the displacement of sand layer and the variation of pore water pressure. In the following, the outline of 
transformation and the procedure of analysis will be shown.

The relation between the effective stress and the pore pressure can be expressed by the following equilibrium equation (see Fig.2).

$$
\rho_{w} g h+\sigma_{y}=\rho_{w} g h_{s}+\rho_{m} g y
$$

where, $\sigma_{y}$ : effective stress.

The sum of terms in the right hand side of Eq.(12) is the total loading above the point of depth y. It is common to both cases (1) and (2)in Fig.2.

Considering that $n \approx n_{w}$ and Eq.(4), Eq. (12) can be simplified into the following form.

$$
\sigma_{y}+\rho_{w} g h^{\prime}=\left(\rho_{s}-\rho_{w}\right) g\left(y-y_{*_{0}}\right)(1-n)
$$

The term in the right hand side of Eq.(13) is the effective weight of sand particles above the point of interest in water. It can be regarded as constant term, supposing that $y_{*_{0}}$ is constant during the small time increment.

Effective stress is divided into two part: the effective stress $\sigma_{y 0}$ caused by the weight of sand particles and the effective stress increment $\tilde{\sigma}_{y}$ induced by the excess pore pressure.

$$
\sigma_{y}=\tilde{\sigma}_{y}+\sigma_{y 0}
$$

When the sand bed is in the static state without oscillating water pressure, the excess pore pressure $h^{\prime}$ and the static effective stress $\sigma_{y 0}$ are that,

$$
\left.\begin{array}{rl}
h^{\prime} & =0 \\
\sigma_{y 0} & =\left(\rho_{s}-\rho_{w}\right) g\left(y-y_{*_{0}}\right)(1-n)
\end{array}\right\}
$$

Applying Eq.(14) and Eq.(15), Eq.(13) becomes

$$
\tilde{\sigma}_{y}+\rho_{w} g h^{\prime}=0
$$

Substituting $\tilde{\sigma}_{y} \quad$ in Eq.(13)' with $\tilde{\sigma}_{y}=-\frac{1}{\alpha} \varepsilon=-\frac{1}{\alpha} \frac{\partial \tilde{u}}{\partial y}, \quad$ one obtains

$$
-\frac{1}{\alpha} \frac{\partial \tilde{u}}{\partial y}+\rho_{w} g h^{\prime}=0
$$

where,

$\tilde{u}:$ the displacement of sand layer induced by oscillating water pressure, not including initial displacement.

$\varepsilon \quad:$ strain of sand layer skeleton induced by effective stress $\tilde{\sigma}_{y}$

Differentiating the both sides of Eq.(16) with respect to the coordinate $y$.

$$
\frac{1}{\alpha} \frac{\partial^{2} \tilde{u}}{\partial y^{2}}=\rho_{w} g \frac{\partial h^{\prime}}{\partial y}
$$

It is known from Eq.(6) that

$$
\frac{\partial h^{\prime}}{\partial y}=\frac{\partial \tilde{h}}{\partial y}
$$

According to Eq.(18), Eq.(17) can be rewritten into

$$
\frac{1}{\alpha} \frac{\partial^{2} \tilde{u}}{\partial y^{2}}=\rho_{w} g \frac{\partial \tilde{h}}{\partial y}
$$

Differentiating the both sides of Eq.(16) with respect to time $t$, then,

$$
\rho_{w} g \frac{\partial h^{\prime}}{\partial t}=\frac{1}{\alpha} \frac{\partial}{\partial t}\left(\frac{\partial \tilde{u}}{\partial y}\right)
$$

It is also known from Eq.(4) that

$$
\frac{\partial h_{s}}{\partial t}=\frac{\partial h_{v}}{\partial t}
$$

from Eq.(21) and Eq.(6), we have

$$
\frac{\partial \tilde{h}}{\partial t}=\frac{\partial h^{\prime}}{\partial t}+\frac{\partial h_{s}}{\partial t}
$$

Considering Eq.(20) and Eq.(22), Eq.(11) can be transformed into

$$
\rho_{w} g\left(\beta n_{w}+\frac{n_{a}}{P}\right) \frac{\partial \tilde{h}}{\partial t}+\frac{\partial}{\partial t}\left(\frac{\partial \tilde{u}}{\partial y}\right)=k \frac{\partial^{2} \tilde{h}}{\partial y^{2}}
$$

When the oscillating water pressure is exerted on the sand surface, basic equations (19) and (23) applied to the un-liquefied sand layer are solved under boundary conditions (24) and initial condition (25) to find the variation of pore water pressure $\tilde{h}$ and the displacement of the sand layer $\tilde{u}$.

The boundary conditions of sand bed at the upper surface of the un-liquefied sand layer $\left(h^{\prime}=0\right)$ and the bottom of sand bed (impermeable, fixed) are as follows:

$$
\left.\begin{array}{c}
\tilde{h}=\frac{(1-n)\left(\rho_{s}-\rho_{w}\right)}{\rho_{w}} y_{*_{0}}+h_{v} \text { at } y=y_{*_{0}} \\
\frac{\partial \tilde{h}}{\partial y}=0, \tilde{u}=0 \quad \text { at } \quad y=D
\end{array}\right\}
$$

At the beginning of excitation, the excess pore pressure and the liquefaction don't occur in the sand bed. Then, the initial condition is given as following:

$$
y_{*_{0}}=0, \tilde{h}=0, \quad \text { at } \mathrm{t}=0
$$

Finite element method was applied with respect to spatial differentiation, and finite difference method was applied with respect to time differentiation.

Excess pore pressures at nodes are calculated by Eq.(8) with the pore water pressure $\tilde{h}$ found from Eq.(19) and Eq.(23).

Then, the effective stress can be calculated by using the above Eq.(13), when excess pore pressure $h^{\prime}$ is known.

If the stress $\sigma_{y}$ at some position deeper than the liquefied zone $\left(y_{*_{0}}\right)$ becomes zero, the corresponding liquefaction depth $y_{*}$ is also obtained from Eq.(13) 
as follows:

$$
y_{*}=\frac{\rho_{w} g h^{\prime}}{\left(\rho_{s}-\rho_{w}\right) g(1-n)}+y_{* 0}
$$

The value of $n_{a}$ in the sand bed varies with the position due to pressure change. $n_{a}$ is denoted as $\overline{n_{a}}$ under the standard pressure $\left(\bar{P}=P_{0}+\bar{p}\right)$. Then, $n_{a}$ for the pressure $P$ is expressed as follows.

$$
n_{a}=(\bar{P} / P) \times \overline{n_{a}}
$$

The upper boundary surface of the un-liquefied sand bed varies with the change of liquefaction depth. With the increase of liquefaction depth, the sand layer above the liquefaction depth is transformed from solid state to mixed liquid state, and the oscillatory excess pore pressure and the effective stress in this zone become zero. The load acted on the upper boundary of the un-liquefied sand layer increases with the increase of liquefaction depth.

\section{(3) Analysis Approach}

Until now, basic equations (19) and (23) were used to solve the problems about the second stage of liquefaction (Nago ${ }^{3), 5)}$ ).

In the progressive liquefaction process of loosely deposited sand bed, the skeleton of sand bed shows the plastic deformation when effective stress exceeds its yield effective stress, because the porosity in loosely deposited sand bed is rather large (about 0.48 ).

The characteristics of plastic deformation of loosely deposited sand bed are taken into account in this analysis to the progressive liquefaction process. The relationship between effective stress and strain of sand bed skeleton is simplified as shown in Fig.3. In Fig.3,

$\alpha \quad$ : elastic compressibility of the skeleton of sand bed

$\alpha_{1}$ : plastic compressibility of the skeleton of sand bed $\left(\alpha_{l} / \alpha \approx 100\right.$ in general, according to Gotoh ${ }^{15)}$ )

$\sigma_{c}$ : the yield effective stress of the skeleton of sand bed (It is considered that this value is largely influenced by the porosity of sand bed)

$\varepsilon_{c} \quad$ : elastic strain corresponding to $\sigma_{c}$

$\varepsilon_{e} \quad$ : elastic part of a strain $\varepsilon_{1}$ of point $P_{1}^{\prime}$

$\varepsilon_{p}$ : plastic part of a strain $\varepsilon_{1}$ of point $P_{1}^{\prime}$

The point in Fig.3, which indicates the effective stress-strain relationship of some location of loosely deposited sand bed, moves from point a via $b$ to $c$ with the increase of effective stress, and from $\mathrm{c}$ via $\mathrm{d}$, $\mathrm{e}$ to point $\mathrm{f}$ with the decrease and increase of

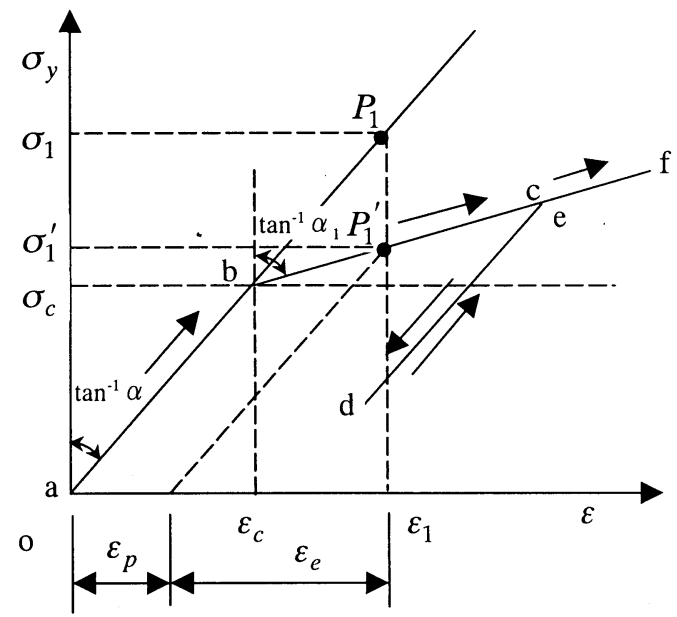

Fig.3 Stress-strain relationship for sand skeleton

effective stress. However, equation (19) is based on the assumption that the skeleton of sand bed is deformed as elastic material. Therefore, the point $P_{1}$, calculated from equations (19), (23) and (13) on the elastic deformation relationship, has to be revised to the point $P_{1}^{\prime}$ according to the effective stress-strain relationship of sand bed skeleton, when the effective stress of the point $P_{1}$ exceeds the yield effective stress of the sand bed. The effective stress $\sigma_{1}$ of the point $P_{1}$ is divided into two parts, one part is the effective stress $\sigma_{1}^{\prime}$ that takes account of plastic deformation of sand bed, and the other is the difference of effective stress $\left(\sigma_{1}-\sigma_{1}^{\prime}\right)$ that is transformed into the excess pore water pressure.

Here, it is assumed that

$$
\sigma_{c}=\sigma_{c}^{\prime} \times\left(\rho-\rho_{w}\right) g\left(y-y_{*_{0}}\right)(1-n)
$$

where $\sigma_{c}^{\prime}$ is the yield effective stress in nondimensional form, which changes for each case.

The concrete procedures of analysis are as follows:

1) The variation of pore water pressure $\tilde{h}$ at every node of sand bed is found by solving the equations (19) and (23) under the boundary condition (24) and the initial condition (25), and the effective stresses are determined by Eq.(13);

2) Whether the effective stresses for each node are larger than the yield effective stresses or not is diagnosed. If the effective stresses of some nodes are larger than the yield effective stresses, the effective stresses at these nodes are revised from $\sigma_{1}$ to $\sigma_{1}^{\prime}$ according to the stress-strain relationship of sand bed skeleton. If not, the effective stress is not revised;

3) The revised effective stresses at some nodes 


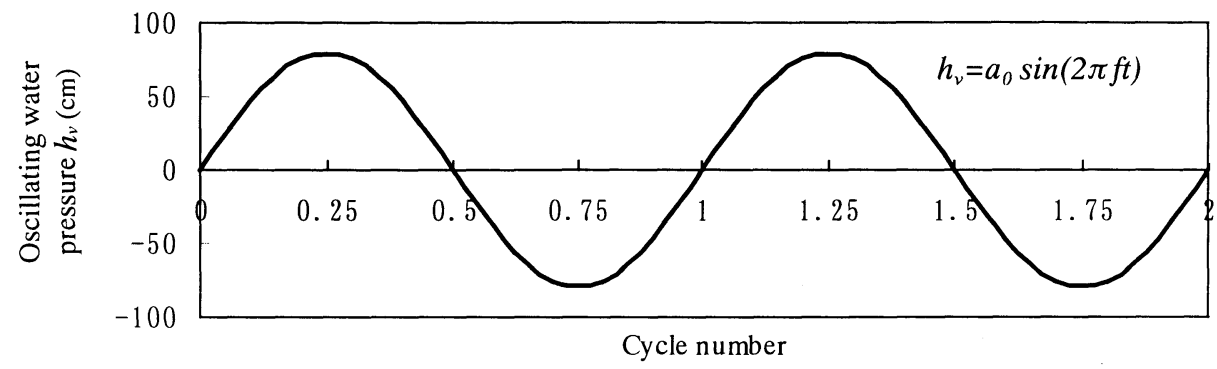

Fig.4 Oscillating water pressure on the water surface

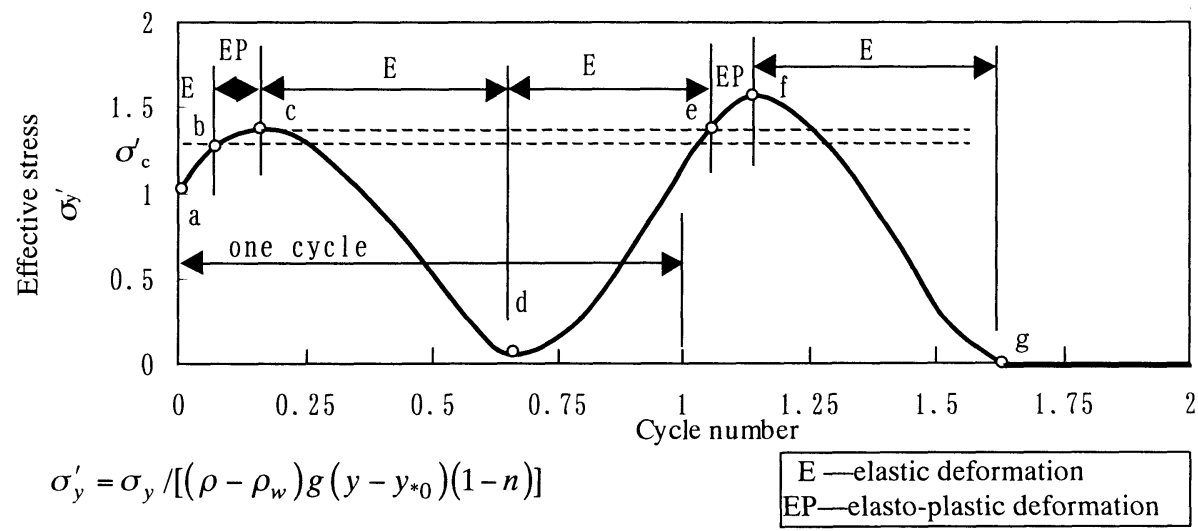

Fig.5 Schema of effective stress at a point of some depth in the sand bed

in plastic zone and the effective stresses at other nodes in elastic zone are put into the equations (19) and (23), and then the equations (19) and (23) are solved to find the variation of pore water pressure $\tilde{h}$ and the displacement $\tilde{u}$ at nodes.

The oscillating water pressure acting on the water surface is shown in Fig.4. The effective stress at a point of some depth in sand bed under the above oscillating water pressure is shown in Fig.5. In the stage of the increase of effective stress, the sand layer at this point lies in the elastic strain state, when the effective stress is less than the yielding effective stress (a-b). The sand layer goes into the elasto-plastic strain state, when the effective stress exceeds the yielding effective stress (b-c). In the stage of the decrease of effective stress, the sand layer again enters the elastic strain state (c-d). Subsequently, the sand layer varies from the elastic strain state via the elasto-plastic strain state to the elastic strain state, as shown in Fig.5. The effective stress becomes zero at about 1.6 cycle number. That is, the sand layer above the point in the sand bed is liquefied.

\section{(4) Numerical Solution by Finite Element Method}

In the following theoretical treatment, the sinusoidally varying water pressure is adopted as the pressure acting on the water surface, that is,

$$
h_{v}=a_{0} \sin (2 \pi f t)
$$

Then, the oscillating water pressure $h_{\mathrm{s}}$ acting on the sand surface is.

$$
h_{s}=h_{0}+a_{0} \sin (2 \pi f t)
$$

where,

$h_{0}$ : still water depth acted on the sand surface in water head

$a_{0}$ : amplitude of pressure variation in water head

$f \quad$ : frequency of pressure variation

a) The characteristics of pore water pressure and effective stress

Fig.6 and Fig.7 show the progressive process of pore water pressure with time and in depth respectively. These are obtained from the numerical analysis with the above method.

The parameter conditions in the numerical 


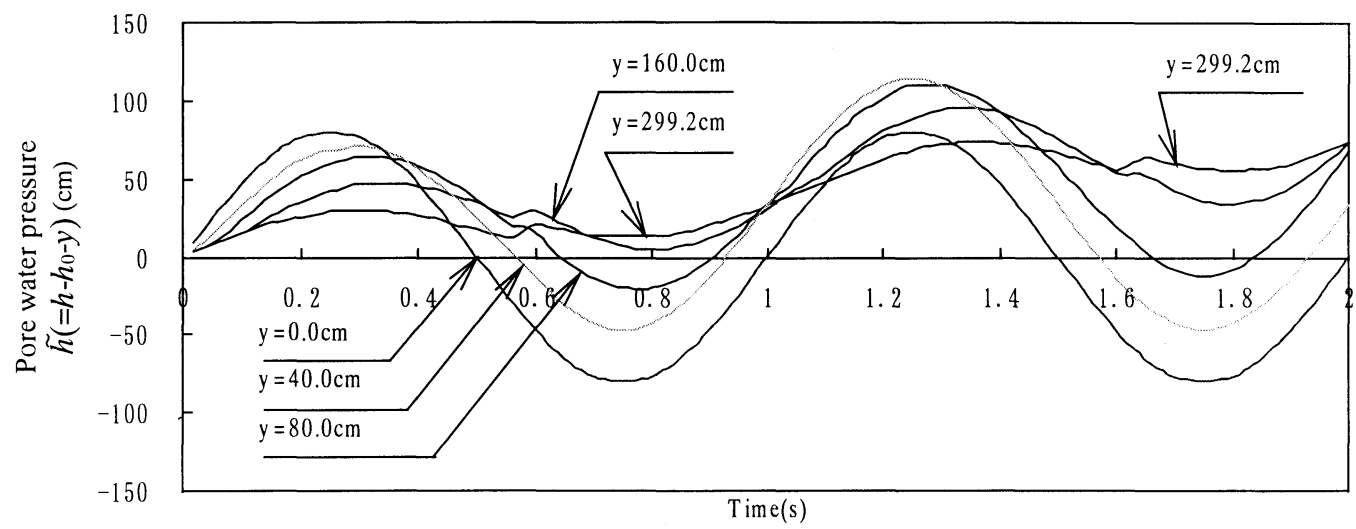

Fig.6 Variation of pore pressure with time
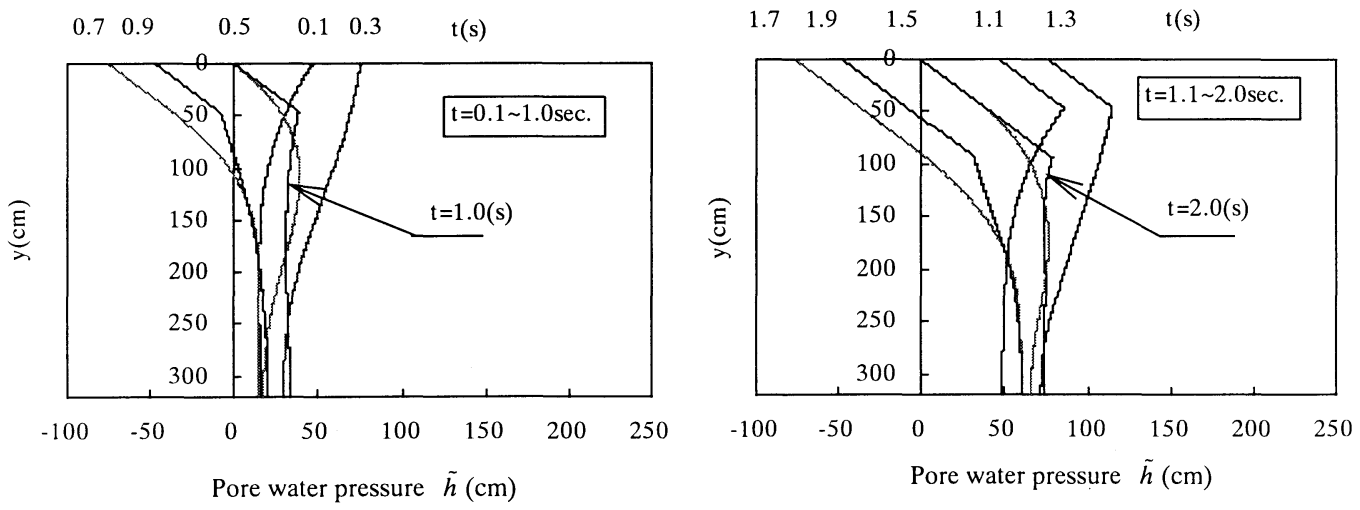

Fig.7 Variation of pore pressure with depth

analysis are given as follows, $n_{a}=0.0022$, $k=0.042 \mathrm{~cm} / \mathrm{s}, n_{w}=0.48, \alpha=6 \times 10^{-9} \mathrm{~m}^{2} / \mathrm{N}, \alpha_{I}=100 \times \alpha$, $\sigma_{c}^{\prime}=1.28, \quad \beta=4.3 \times 10^{-10} \mathrm{~m}^{2} / \mathrm{N}, \quad D=320 \mathrm{~cm}$, $h_{0}=100 \mathrm{~cm}, a_{0}=80 \mathrm{~cm}, f=1.0 \mathrm{~Hz}, \bar{p} / \rho \mathrm{g}=30 \mathrm{~cm}$, $\rho=2.65 \mathrm{~g} / \mathrm{cm}^{3}, \Delta t=0.02 \mathrm{sec}$., $\Delta y=0.53 \mathrm{~cm}$.

Here, the permeability coefficient $k$ is determined by the permeability test of the sand layer in laboratory. Porosity $n_{a}$ and compressibility $\alpha$ are assumed according to the experience of the previous numerical analysis. These values are in agreement with the values used in our previous numerical analysis in order, respectively. Yielding effective stress $\sigma_{c}^{\prime}$ is optimized from the comparison between the curve calculated by the numerical analysis and the curve obtained from the laboratory test for many cases.

Fig.6 shows that the pore pressures at different depths vary with time. The pore pressure at deeper locations remarkably increase with the progress of the liquefaction of sand layer. For example, the cyclical average of pore pressure at $y=299.2 \mathrm{~cm}$ becomes large conspicuously, because the load on the interface between sand layer and mixed fluid becomes larger due to the liquefaction of upper sand layer.

Fig.7 shows that the variation of pore pressure on the sand surface propagates into the sand bed. The pore pressure in un-liquefied sand layer varies with the damp in amplitude and lag in phase. Its characteristics are similar to those described in Nago (1987) ${ }^{5)}$. However, the cyclical average of pore pressure at the bottom of sand bed in the second cycle is larger than that in the first cycle. The pore pressure curve is a straight line in the liquefied zone, because the sand layer in the zone transformed into a mixed fluid composed of sand particles and water.

Fig.8 and Fig.9 show the progressive process of the effective stress with time and in depth respectively, which were calculated from Eq.(13) using the pore pressure values given in Fig.6 .

Fig. 8 shows that the effective stresses at different depths decrease with time, some of which become zero at a certain time, that is, the sand layer in that zone was liquefied. For example, the effective stress at $y=40.0 \mathrm{~cm}$ becomes null from about $0.6 \mathrm{~s}$ and the 


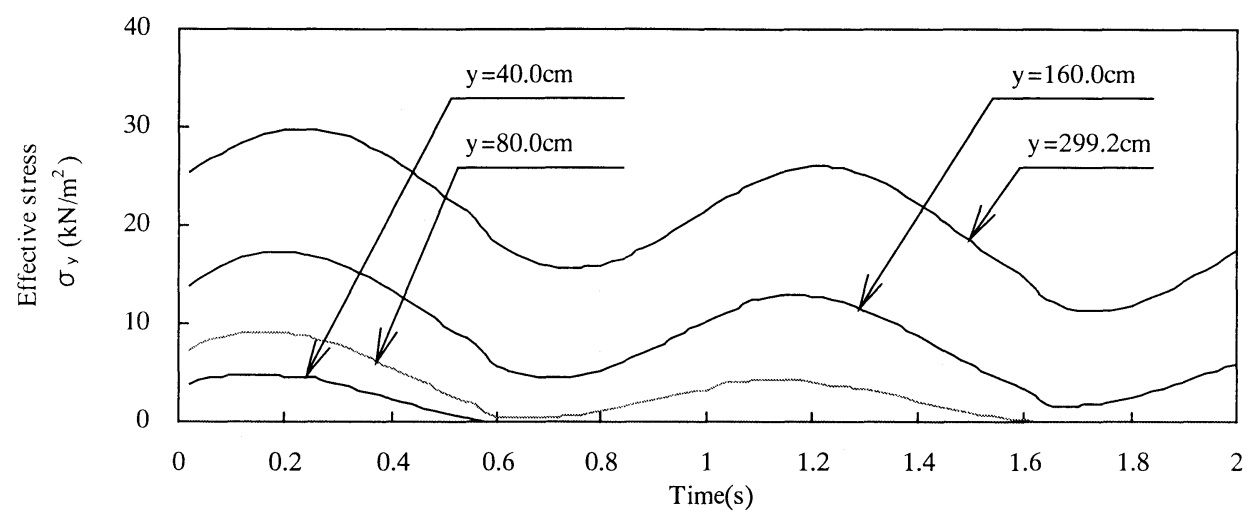

Fig.8 Variation of effective stress with time

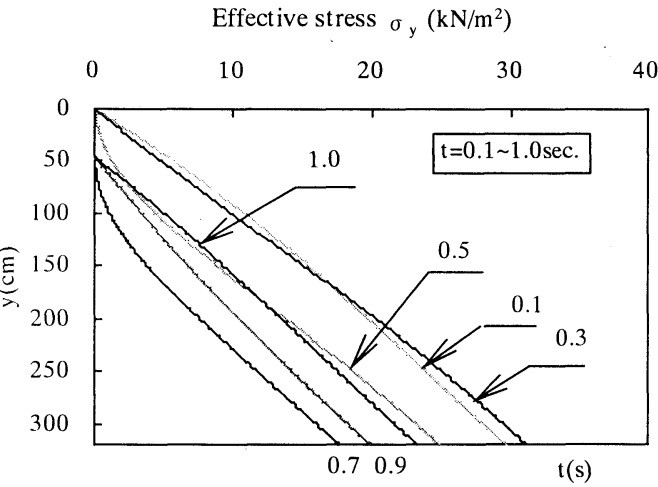

40

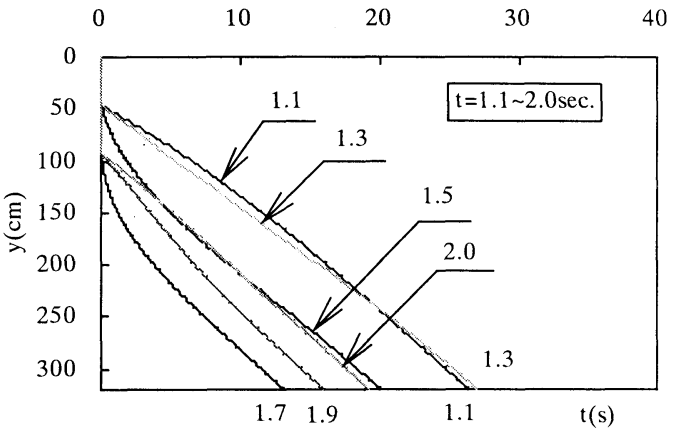

Fig.9 Variation of effective stress with depth

Time(sec.)
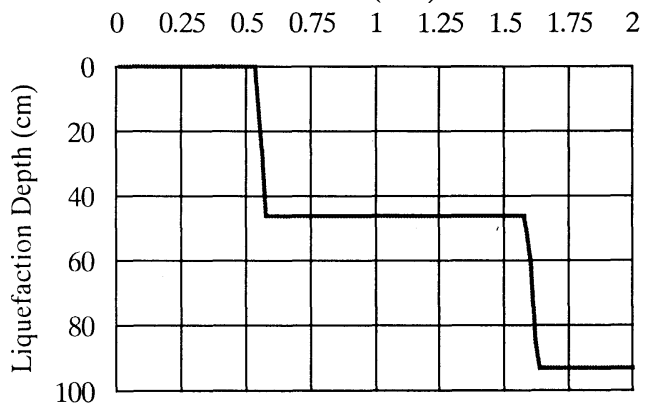

Fig.10 Progressive process of liquefaction

effective stress at $\mathrm{y}=80.0 \mathrm{~cm}$ becomes null from about $1.6 \mathrm{~s}$.

It is seen in Fig.9 that the liquefied zone, in which the effective stress is equal to zero, increases with the time of cyclical loading.

Fig.10 shows that the liquefaction depth progresses with time, and that the liquefaction occurs between $0.5 \mathrm{~s}$ and $0.75 \mathrm{~s}$ and between $1.5 \mathrm{~s}$ and
$1.75 \mathrm{~s}$ during the decrease of oscillating water pressure in this condition. The liquefaction depth is about $90 \mathrm{~cm}$ at $1.75 \mathrm{~s}$.

(b) The comparison of numerical solutions by the elastic model and by the elasto-plastic model

The comparisons of the numerical solutions by the elastic model and by the elasto-plastic model at point $80 \mathrm{~cm}$ deep on the case mentioned in the former section (1) are shown in Fig.11 Fig.13.

It can be understood from Fig.11 and Fig.12 that the pore water pressure by the elasto-plastic model is larger than one by the elastic model, and that the effective stress by the elasto-plastic model is less than one by the elastic model. The sand bed model considering the elasto-plasticity shows that the liquefaction will develop easier. The point $80 \mathrm{~cm}$ deep in elasto-plastic model is liquefied at about 1.6 second, when the effective stress in Fig.12 becomes zero. Fig.13 shows the variation of the strain of sand layer skeleton in sand bed with time, which was calculated with the difference of displacements of sand layer at nodes. It is known from Fig.13 that the strain of sand skeleton in the elasto-plastic model 


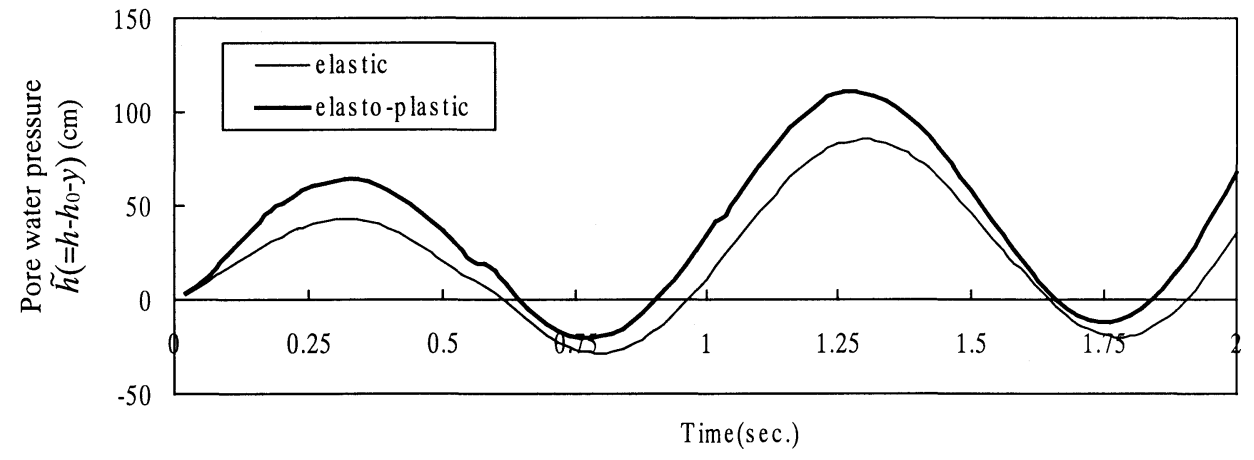

Fig.11 Pore water pressure at the point $80 \mathrm{~cm}$ in depth

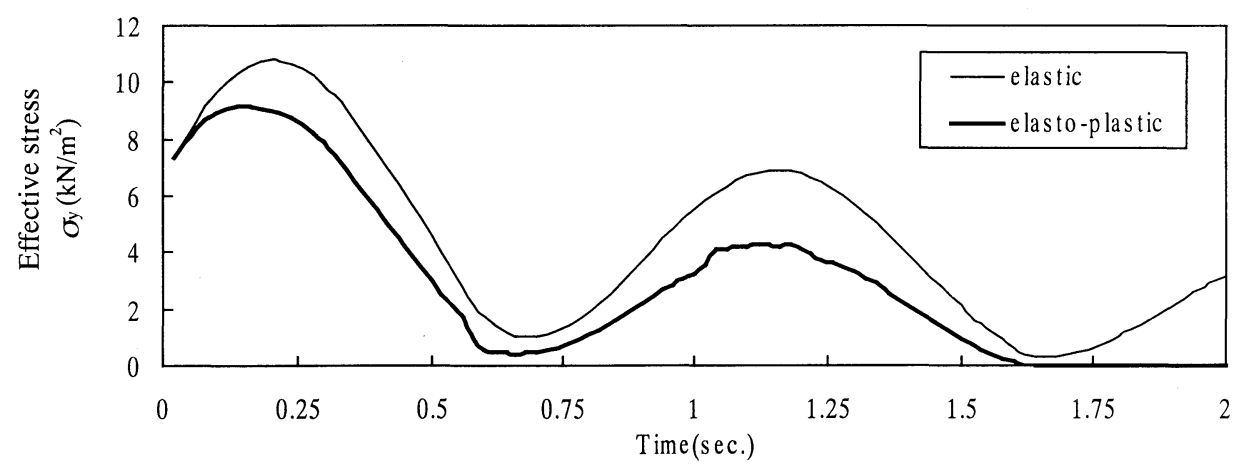

Fig.12 Effective stress at the point $80 \mathrm{~cm}$ in depth

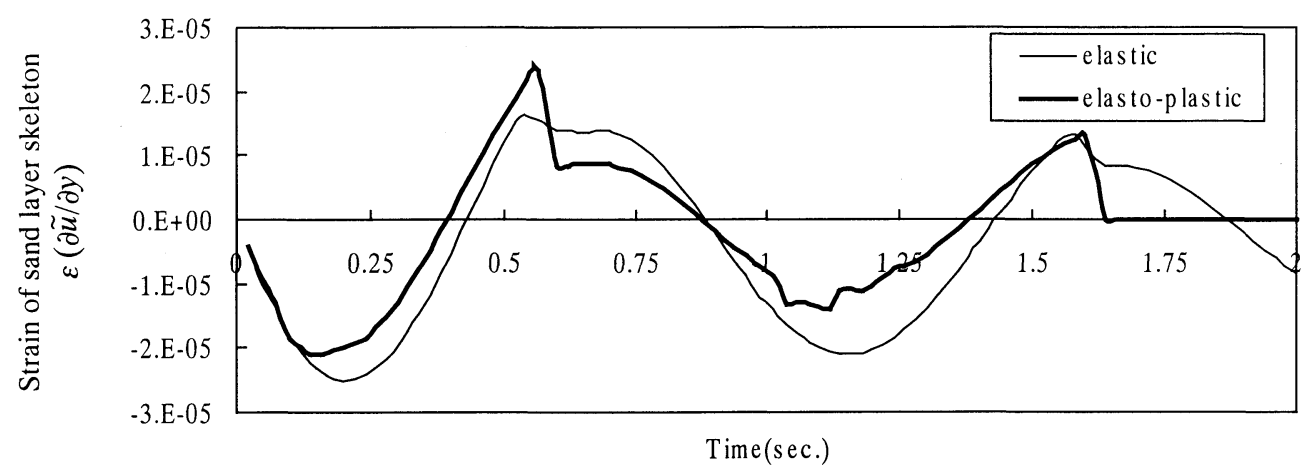

Fig.13 Strain of sand bed skeleton at the point $80 \mathrm{~cm}$ in depth

suddenly changes near the time when liquefaction developed. This phenomenon has not yet been seen in the strain curve obtained by the elastic model. Moreover, the strain curve by the elasto-plastic model is not so smooth as that by the elastic model due to the influence of plasticity.

\section{EXPERIMENTAL VERIFICATION}

\section{(1) Experimental procedures}

The vertical cylinder made of lucid acrylic acid resin that is shown in Fig.14 was used as the vessel of sand layer. It is $8.9 \mathrm{~cm}$ in inner diameter and is $326 \mathrm{~cm}$ high. The column was filled with loosely deposited sand to $320 \mathrm{~cm}$ from its bottom, and the water depth above the sand surface was about 
$100 \mathrm{~cm}$. The periodically oscillating air pressure was acted on the water surface. The amplitude of it was about $80 \mathrm{~cm}$ in water head and the frequency was 1.0 $\mathrm{Hz}$. The grain size of sand used in the experiment is $\mathrm{d}_{50}=0.25 \mathrm{~mm}$ (Toyoura sand), and its specific weight is 2.65 . The permeability coefficient of sand layer for the initial state was about $0.04 \mathrm{~cm} / \mathrm{sec}$. The porosity $n$ at the initial state was about 0.48 .

In the experiment, the dried sand was dropped freely into the water in vessel to set up the same sand bed condition for the whole depth of sand layer. The measurement was started when the stationary state was obtained after the finish of dropping. The oscillating water pressure on the sand surface was generated with a generator of oscillating air pressure. The water pressure in the water and in the sand bed was measured by means of pressure transducers attached to the side wall of the cylinder. Pressures were measured continuously from the beginning of the experiment for 10 minutes long with an interval of 0.02 second. The porosity of sand was measured as follows. The sand bed was divided into four cylinders. The mean porosity in each cylinder was obtained by using the volume of each cylinder, the weight of dried sand and the specific weight of sand. The values were adopted as porosity at center of each cylinder.

Pt.1-Pt.8 in Fig.14 are the numbers of the measured points, and their depths from the initial surface of sand bed are $0 \mathrm{~cm}, 40 \mathrm{~cm}, 50 \mathrm{~cm}, 80 \mathrm{~cm}$, $130 \mathrm{~cm}, 160 \mathrm{~cm}, 200 \mathrm{~cm}$ and $300 \mathrm{~cm}$ respectively.

\section{(2) Experimental results}

The pore water pressure measured in the experiment is shown in Fig.15, and the corresponding effective stresses are shown in Fig.16, which were calculated with the data in Fig.15. The curves of pore water pressure given in the figure are from the measured points Pt.1 (in water), Pt.2 $(y=40.0 \mathrm{~cm})$, Pt.4 $(y=80.0 \mathrm{~cm})$, Pt.6 $(160.0 \mathrm{~cm})$, Pt.8 $(300.0 \mathrm{~cm})$.

It is understood from Fig.15 that the average of pore pressure per cycle increases with time. This indicates that the sand bed gradually liquefied from upper layer to deeper layer. As shown in Fig.16, the

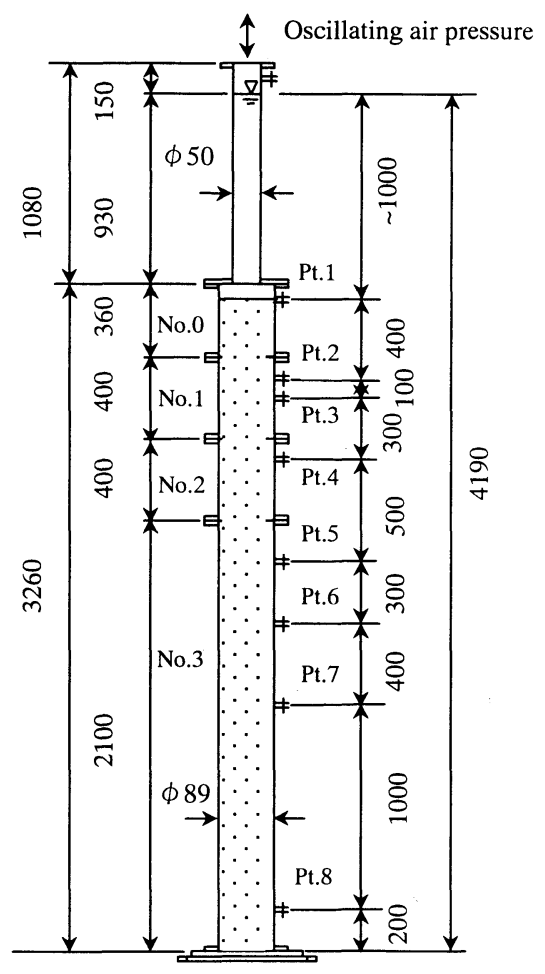

Fig.14 Experimental apparatus (unit:mm)

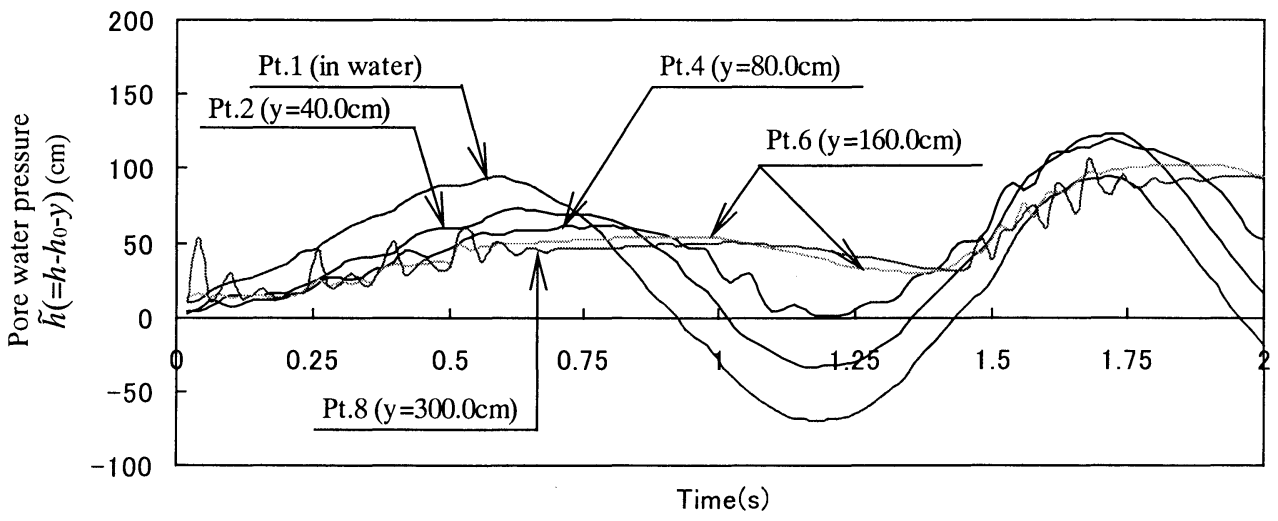

Fig.15 Pore water pressure with time (measured) 


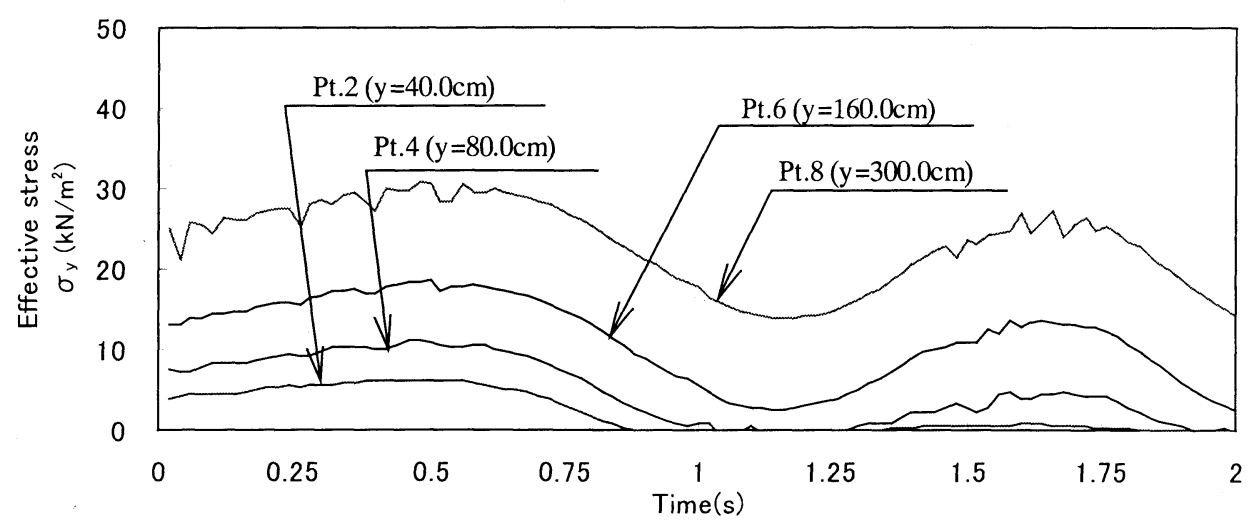

Fig.16 Effective stress with time (calculated with data in Fig.15)
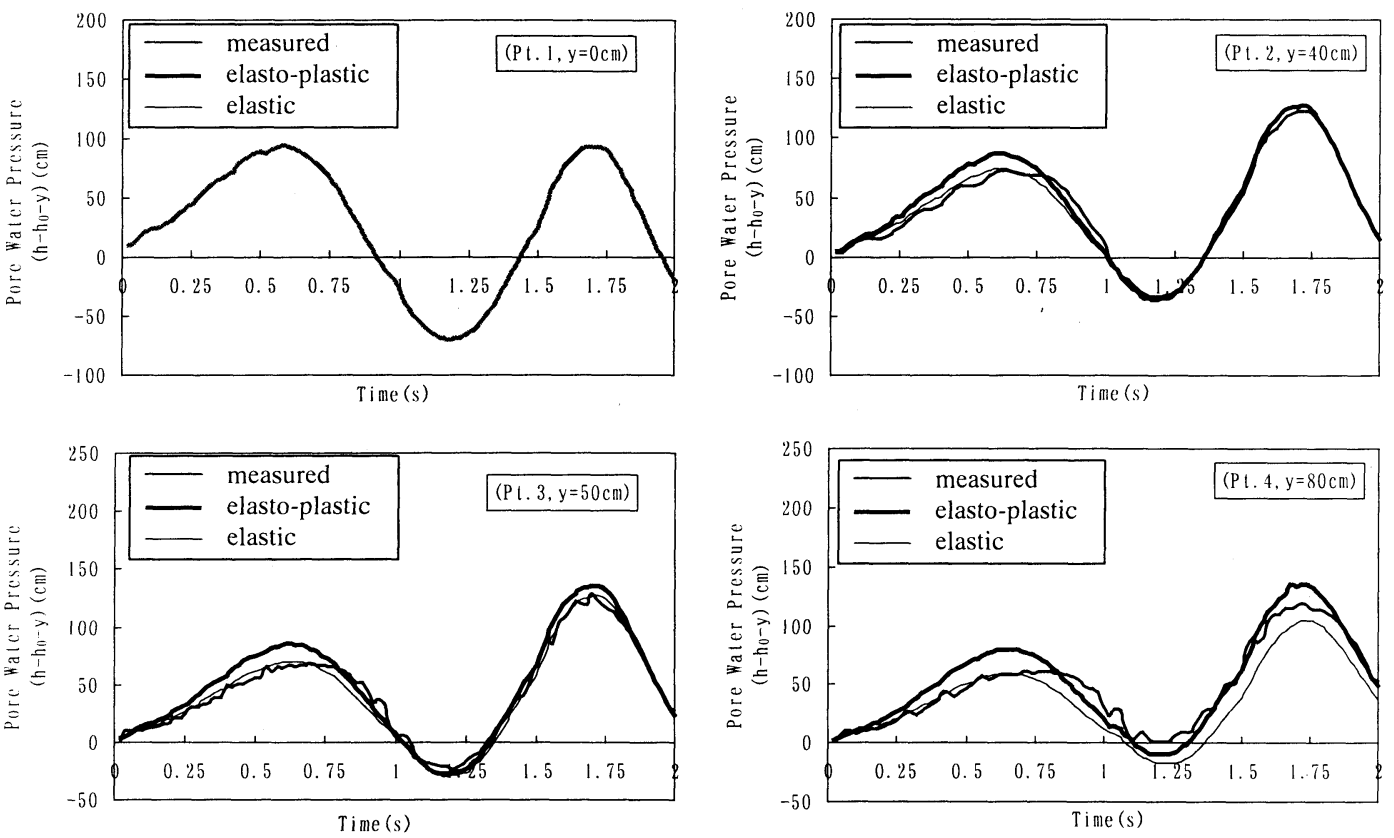

Fig.17 (1) Comparison between the measured and the calculated pore pressure

(Pt.1 Pt.4)

effective stress at Pt.2 becomes zero from 0.85 second. That is, the sand layer above Pt.2 $(y=40.0 \mathrm{~cm})$ have been liquefied. The effective stress at Pt.4 $(\mathrm{y}=80.0 \mathrm{~cm})$ becomes zero from 1 second, recovers later and becomes zero at about 1.9 second more once. It is known from this change of effective stress that the sand layer $80 \mathrm{~cm}$ deep is in the state of cyclic transient liquefaction.

\section{(3) Comparison of the analytical solutions with experimental data}

The pore pressure measured in our experiment, the pore pressure calculated by the elasto-plastic model as well as the pore pressure calculated by the elastic model for the same case are shown in Fig.17.

It is understood from Fig.17 that the pore pressure curve obtained numerically by the elastoplastic model is consistent with the experimental curve, and that the pore pressure curve by the elastic model goes away from the experimental curve with the increase of time. On the elastic model, the liquefaction of the sand bed develops comparatively slowly, and the pore water pressure damps rapidly from Pt. 2 to Pt. 8 in the sand bed. It is proved that 

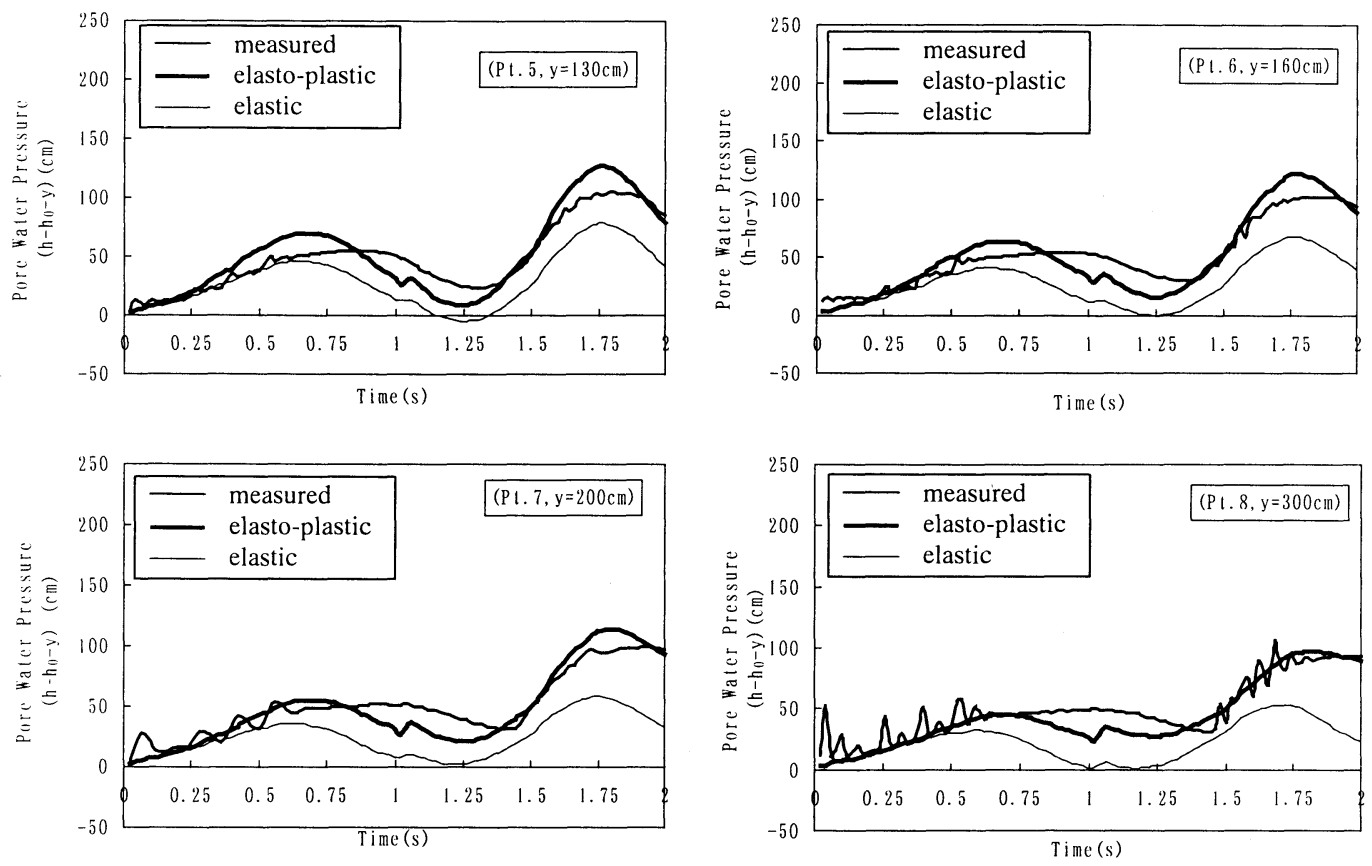

Fig.17 (2) Comparison between the measured and the calculated pore pressure

(Pt.5 Pt.8)

elasto-plastic model can be applied to analyze the progressive liquefaction process.

The liquefaction depths of sand bed at time $(\mathrm{t}=2 \mathrm{~s})$ are $74 \mathrm{~cm}$ for the experiment, $76.8 \mathrm{~cm}$ for the elastoplastic model, $45 \mathrm{~cm}$ for the elastic model, respectively. However, the change of the porosity with time and the subsidence of sand in liquefied zone is not considered in this analysis, because it is very short for the oscillating water pressure to be exerted. The change of the porosity due to densification of sand should be taken into account in the analysis of the process from the first stage of liquefaction to the second stage of liquefaction. Because we could not detect the exact values of the air porosity, the compressibility of sand layer and yielding effective stress, it was assumed in the instance that $n_{a}=0.0022, \alpha=6 \times 10^{-9} \quad\left(\mathrm{~m}^{2} / \mathrm{N}\right)$, $\sigma_{c}^{\prime}=1.28$. The porosity $n$ at the initial state in this case was 0.486 . The permeability coefficient is $k=0.042(\mathrm{~cm} / \mathrm{sec})$.

\section{CONCLUSIONS}

The progressive processes of the pore water pressure and the effective stress with time in a loosely deposited sand bed under oscillating water pressure on the sand surface during the first type of liquefaction were investigated theoretically by using the vertically one-dimensional model, and compared with experimental results. The conclusions can be drawn as follows:

(1) It is clear that the numerical solutions taken account of the elasto-plasticity of the sand bed skeleton fairly well reproduced the progressive liquefaction process of sand bed during the first type of liquefaction.

(2) The sand bed model considering the elastoplasticity shows that the liquefaction will develop easier than one by the elastic model.

(3) The change of the porosity with time and the subsidence of sand in liquefied zone were not considered in this analysis. The change of the porosity due to densification of sand should be taken into account in the analysis of the process from the first stage of liquefaction to the second stage of liquefaction.

(4) In this study, the values of the air porosity, the compressibility and the yield effective stress of sand bed in the numerical analysis were assumed. It is necessary to make clear the characteristic values of these properties in further research.

ACKNOWLEDGEMENTS: The authors wish to express their gratitude to graduate student $\mathrm{Mr}$. Hitoshi INO for his cooperation in the experiment.

This research was partly supported by a Grant-in- 
Aid for Scientific Research (C) (1998,1999, No.10650508) and (B) (2000, No.12450202) from the Japanese Ministry of Education, Science, Sports and Culture. We are grateful for this support.

\section{REFERENCES}

1) Madsen, O.S.: "Wave-induced pore pressure and effective stresses in a porous bed", Geotechnique, Vol. 28, No.4, pp.377-393. 1978.

2) Yamamoto, T., Koning, H. L., Sellmeijer, H. and Hijum, E. : " On the response of a poro-elastic bed to water waves ", J. Fluid Mech., Vol. 87, No.1, pp. 193-206, 1978.

3) Nago, H. : "Liquefaction of Highly Saturated Sand Layer under Oscillating Water Pressure", Memoirs of the School of Engineering, Okayama University, Vol.16, No.1, pp.91104. 1981.

4) Nago, H. and Maeno, S. : "Pore Water Pressure in Sand Bed under Oscillating Water Pressure", Memoirs of the School of Engineering, Okayama University, Vol.19, No.1, pp.13-32. 1984.

5) Nago, H. and Maeno, S. : "Pore Pressure and Effective Stress in A Highly Saturated Sand Bed Under Water Pressure Variation on Its Surface", Natural Disaster Science, Volume 9, Number 1,pp.23-35. 1987

6) Okusa, S. : "Wave-induced stresses in unsturated submarine sediments", Geotechnique, Vol.35, No.4, pp.517-532. 1985.

7) Sakai, T., Hatanaka, K. and Mase, H. : “Applicability of Solutions for Transient Wave-induced Porewater Pressures in Seabed and Liquefaction Conditions of Seabed", Proceedings of JSCE, No.417/2-13, pp.275-283. May, 1990.(in Japanese)
8) Miura, K., Hayashi, M. and Yoshida, N. : "Applicability of Analytical Methods for Seabed Response to Ocean Waves", Proceedings of the international symposium Geocoast'91, Yokohama, pp. 609-614, 3-6,Sept., 1991.

9) Sassa, S. and Sekiguchi, H. : "Wave-induced liquefaction of beds of sand in a centrifuge", Geotechnique, Vol. 49, No. 5, pp. 621-638, 1999.

10) Zen, K., Yamazaki, H. and Watanabe, A. : "Wave-induced Liquefaction and Densification in Seabed ", Report of the Port and Harbour Research Institute, Vol. 26, No. 4, 1987.(in Japanese)

11) Oka, F., Yashima, A., Shibata, T. and Kato, M. : " A finite element analysis of liquefaction of seabed due to wave action", Proceedings of the international symposium Geocoast'91, Yokohama, pp. 621-626, 3-6,Sept., 1991.

12) Kuwabara, H. and Tamai, S. : "Wave-induced Elastoplastic Behavior of Ground around Breakwater ", Proceeding of Coastal Engineering, JSCE, Vol.39, pp.861865. 1992. (in Japanese)

13) Sekiguchi, H., Kita, K. \& Okamoto, O. : "Response of poro-elastoplastic beds to standing waves". Soils Found, Vol. 35, No. 3, pp. 31-42, 1995.

14) Nago, H., Maeno, S., Matsumoto, T. and Hachiman, Y. : "Liquefaction and Densification of Loosely Deposited Sand Bed Under Water Pressure Variation", Proceedings of the Third International Offshore and Polar Engineering Conference, Singapore, 6-11 June, 1993.

15) Gotoh, M. : "Engineering Finite Element Method For Analysis of Large Elasto-plastic Deformation", Korona Publishing Co.Ltd, 1995. (in Japanese)

(Received October 20, 1999)

\title{
変動水圧作用下における緩い堆積砂層の進行性液状化過程
}

\author{
于月増・前野詩朗・名合宏之
}

\begin{abstract}
本文では, 変動水圧による緩い堆積砂層の進行性液状化過程を鈶直 1 次元砂層モデルを用いて理論的 かつ実験的に検討した. 本研究で用いた砂層の弾塑性特性を考慮した数学モデルによる解析結果は, 周期 的な変動水圧が作用した場合の初期段階における砂層内の間隙水圧分布特性をよく説明しており, 平均間 隙水圧の上昇を伴う進行性液状化過程をほぼ再現しうるものであることが明らかとなった.
\end{abstract}

